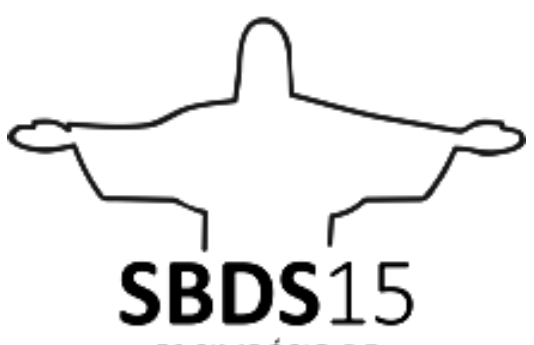

5 SIMPÓSIO DE

DESIGN SUSTENTAVEL

Rio de Janeiro, 11 de novembro a 13 de novembro de 2015

\title{
REAPROVEITAMENTO DE CAMISAS MASCULINAS NA MARCA COMAS: uso do conceito upcycling
}

\author{
Bruna Lummertz Lima \\ Universidade Federal do Rio Grande do Sul \\ Centro Universitário Metodista IPA \\ brunalummertz@hotmail.com
}

Resumo: Esse trabalho versa sobre o conceito upcycling e sua utilização como princípio em uma marca de moda que por meio do reaproveitamento de peças de vestuário, oriundas de uma fábrica de camisas masculinas, estabeleceu seu conceito e design diferenciado. O estudo apresenta no referencial teórico as etapas do processo de produção do produto de moda com os resíduos gerados ao longo do mesmo. Em sequência, aborda o conceito de upcycling e a forma como é implementado na marca de moda feminina Comas, ao longo do desenvolvimento dos artigos de vestuário. Por fim, apresenta uma análise descritiva acerca do processo produtivo bem como as considerações finais.

Palavras-chave: indústria têxtil, indústria de moda, processo de produção, upcycling.

Abstract: This work deals with the upcycling concept and its use as a principle in a fashion brand which through the reuse of garments, coming from a factory of men's shirts, established his concept and distinctive design. The study presents the theoretical stages of the production process of the fashion product with the waste generated over the same. In sequence, addresses the concept of upcycling and the way is implemented in the fashion brand women Comas, throughout the development of the garments. Finally, it presents a descriptive analysis about the production process and the final remarks.

Keywords: textile industry, fashion industry, production process, upcycling. 


\section{INTRODUÇÃO}

A indústria têxtil brasileira é a quinta maior do mundo, mas participa com menos de $0,4 \%$ desse mercado. Os asiáticos, com mais de $50 \%$ da produção têxtil mundial, são os maiores exportadores, produtores, empregadores, produtores de algodão, investidores e possuem as maiores empresas do setor no mundo. Considerando a produção de vestuário, segmento no qual o custo da mão-de-obra é a variável fundamental na busca pela competitividade, os três principais produtores mundiais estão localizados na Ásia - China/Hong Kong (43,5\% do total produzido), Índia (6,3\%) e Paquistão (3,7\%). (BNDES, 2009).

A produção deste setor inicia com a transformação das fibras têxteis em fio nas fábricas de fiação. Este processo compreende algumas operações onde as fibras são abertas, limpas e orientadas em uma mesma direção. Além disso, são paralelizadas e torcidas de modo a se prenderem uma as outras por atrito. Em seguida, o fio segue para a tecelagem ou para a malharia, onde é transformado em tecido plano ou em malha, respectivamente (CHATAIGNIER, 2006; PEZZOLO, 2007).

Posteriormente, passa pela etapa de beneficiamento que consiste em um conjunto de processos aplicados aos materiais têxteis para transformá-los, a partir do estado natural, em artigos brancos, estampados, tingidos e acabados (ANDRADE FILHO; SANTOS, 1987 apud TWARDOKUS, 2004). Por fim, ocorre a confecção de artigos de cama, mesa e banho, bem como de vestuário ou acessórios de moda (BNDES,2009).

Os maiores poluentes da indústria têxtil são o resultado da penúltima etapa citada, conhecida como beneficiamento. Nela se concentram o maior número de substâncias químicas e processos de intensos riscos ambientais e poluidores. As emissões destes poluentes líquidos causam grande contaminação no ambiente, dependendo do tipo de fibras processadas e dos produtos químicos empregados (SANTOS, 1996).

Quanto a água, sua utilização ocorre basicamente em todas as fases do processo, direta ou indiretamente. É direta nos processos de lavagem, tingimento e amaciamento, e indireta no aquecimento ou resfriamento da malha de algodão (MARTINS, 1997). A água é utilizada como condutor para os produtos químicos que entram no processo, bem como para a remoção do excesso dos produtos considerados indesejáveis para o substrato têxtil. A maior parte da carga contamina rios e lagos pois contém produtos químicos auxiliares e corantes eliminados durantes as diferentes etapas do acabamento (TWARDOKUS, 2004). Além disso, a indústria têxtil apresenta em seus sistemas de vapor e secagem de tecidos, grande quantidade de emissões atmosféricas, geradas, sobretudo, em consequências dos amaciantes utilizados (MARTINS, 1997).

Diante deste cenário, a indústria da moda grande utilizadora de têxteis, vem passando por mudanças significativas na forma de criar e produzir artigos de vestuário. Preocupados com o impacto da indústria têxtil sobre o meio ambiente, estilistas de Londres, Berlim, Amsterdã, Nova lorque e Los Angeles vêm repensando o universo da 
moda há cerca de cinco anos, visando valorizar o processo de confeç̧ão do vestuário e não descartar tão brevemente peças de roupa em bom estado. Práticas como o uso de matérias-primas orgânicas e não poluentes, roupas multifuncionais ou modulares construídas a partir de peças encaixáveis, design sem resíduos ${ }^{1}$ ou gestão de resíduos, para o descarte adequado são algumas das constantemente utilizadas (COMAS, 2015).

Do ato de repensar o ciclo de vida dos produtos de moda, com ênfase na etapa de descarte prematuro, surgiu o conceito upcycling, que traduzido para o português significa valorizar o ciclo. Para Anicet et. al. (2011) significa usar um material já utilizado ou o resíduo de um produto tal como foi encontrado, sem despender de mais energia na reutilização do mesmo. É um processo de recuperação que transforma os resíduos desperdiçados em novos produtos ou materiais com superior qualidade e valor ambiental. No sentido amplo da palavra, a valorização está em ampliar a utilização dos produtos, que seriam descartados por conta dos controles rigorosos de qualidade nas suas fábricas de origem.

Neste sentido, o presente trabalho irá apresentar uma análise baseada em pesquisa bibliográfica, realizada acerca do trabalho da estilista Uruguaia Agustina Comas, que em marca própria realiza a concepção e o desenvolvimento de suas peças, utilizando o conceito do Upcycling. Essa valorização na marca Comas, consiste no reaproveitamento de camisas masculinas, para gerar novos produtos femininos.

Nas próximas seções, esse estudo irá apresentar inicialmente no referencial teórico, o processo de desenvolvimento e produção do produto de moda, enfocando os resíduos gerados em cada etapa. Em seguida, irá delinear e analisar o processo produtivo da marca Comas, guiado pelo conceito do Upcycling e por fim irá apresentar as considerações finais.

\section{DESENVOLVIMENTO}

\subsection{Referencial Teórico}

Pertencentes a indústria têxtil, as empresas de moda a cada estação desenvolvem uma coleção de moda, que consiste em um conjunto de produtos, com harmonia do ponto de vista estético ou comercial, cuja fabricação e entrega são previstas para determinadas épocas do ano (RECH, 2002).

Para essa concepção, algumas particularidades são consideradas e contemplam fases de produção de uma peça de vestuário fracionadas (RECH, 2006). Dependendo de produto a ser produzido, seus detalhes e acabamentos podem agregar ou reduzir etapas. Basicamente, o caminho que o produto percorre está centrado em etapas de planejamento, pesquisa, desenvolvimento, pilotagem e produção (TREPTOW, 2013).

\footnotetext{
${ }^{1} \mathrm{Na}$ moda o zero waste tem como objetivo o aproveitamento total do tecido, sem gerar resíduos, por meio de alterações na modelagem, podendo ser classificado em dois tipos. No primeiro, a modelagem é concebida através de moldes que se encaixam perfeitamente e ocupam toda a extensão do tecido, não sobrando nenhum resíduo. E, no segundo tipo, os moldes podem ser tradicionais, mas o resíduo gerado será reutilizado ou reciclado. (ANICET; RÜTHSCHILLING, 2013, p. 06).
} 
Inicialmente, a peça criada por meio de um desenho de moda é em seguida reproduzida por meio de um desenho técnico. Frings (2012) define este como um desenho proporcional que mostra todos os detalhes da peça, incluindo a linha de costura e os aviamentos. Este desenho consiste em uma representação planificada da roupa, com especificações de corte, materiais e acabamentos que irão compor uma ficha de trabalho, denominada de ficha técnica. Segundo Treptow (2013) a ficha técnica é o documento descritivo de uma peça da coleção e é imprescindível que seja construída de uma forma clara, completa e objetiva para que o modelista entenda e, assim, auxilie o seu trabalho.

O processo posterior à elaboração da ficha técnica é a modelagem. De acordo com Souza (2010, p.341) "a modelagem é a técnica responsável pelo desenvolvimento das formas da vestimenta, transformando materiais têxteis em produtos de vestuário". A modelagem constrói a criação do produto de moda e por meio dela a criação adquire a terceira dimensão.

No próximo momento, a peça que foi modelada é cortada e costurada no chamado processo de pilotagem ${ }^{2}$. Após a conclusão da costura, é possível identificar algum erro oriundo da modelagem ou então certificar-se que a peça pode ser produzida em grande escala. Verificando alguma inadequação, a peça volta ao profissional da modelagem para corrigir o erro e posteriormente, retorna ao processo de pilotagem. Se aprovada, segue para a produção na empresa. Sanches (2010) destaca a importância dos protótipos de teste para a avaliação e a seleção de alternativas para a produção de produtos de moda.

A produção em grande escala em empresas de moda inicia com a graduação dos moldes aprovados, que são definidos após a pilotagem. Essa atividade sequente consiste na realização de aumento e diminuição de moldes, pertencentes a uma grade de numeração que tem relação com os tamanhos que a empresa produz para a venda. Frings (2012) exemplifica que a partir de um molde de amostra de tamanho 40 pode ser aumentado para dar conta dos tamanhos ${ }^{3} 42,44$ e 46 e diminuído para os tamanhos 38 e 36.

Após a conclusão da graduação, os moldes originados são posicionados em cima do tecido escolhido para o desenvolvimento da peça, no processo chamado encaixe. Seus objetivos são o maior aproveitamento do tecido e o atendimento às indicações dos moldes realizadas pelo modelista, no que se refere ao fio do tecido, estampa no caso de tecidos estampados e a margem necessária para costura.

O encaixe deve estar adequado à quantidade de peças que deverão ser cortadas. Para Frings (2012), o planejamento de produção eficaz, tem uma ordem de corte, informando o que cortar, que tecidos usar e como cortar. Dependendo do número de peças necessárias, além do encaixe de moldes, o tecido deverá ser enfestado. Conforme Alves (2010), na indústria do vestuário o encaixe de moldes é feito sobre várias camadas de tecido colocadas uma sobre a outra, o enfesto. Com esse processo

\footnotetext{
${ }^{2}$ No design de moda, a palavra pilotagem é utilizada para denominar o processo de confecção da peçapiloto. No design, esse processo é conhecido como prototipação no qual se confeccionam protótipos.

${ }^{3}$ A numeração é definida pelas medidas do corpo humano. Em confeç̧ões de moda, estas constam em uma tabela, composta pelos tamanhos que a empresa utiliza para a produção de vestuário.
} 
finalizado, é realizado o corte que pode ser manual, realizado por máquina de corte ou então por meio de processos computadorizados.

As peças cortadas são encaminhadas para a montagem, onde ocorre a costura. Cada etapa deste processo é chamada de operação e alguns sistemas de organização podem ser utilizados de acordo com cada empresa, a fim de maximizar a produção, melhorar a qualidade dos produtos e evitar perdas. Após a conclusão da costura, as peças são enviadas para o acabamento. Esta atividade consiste na retirada de excessos de linhas de costura na parte externa e interna da roupa. Com o acabamento finalizado, a peça passa pelo controle de qualidade, onde caso sejam observadas inadequações ou erros a peça é descartada. As peças corretas, são aprovadas e encaminhadas ao setor de expedição, onde recebem etiquetas de identificação, os tags e são encaminhadas aos pontos de venda, para serem então consumidas pelo cliente da marca.

Durante as etapas de desenvolvimento e produção do produto de moda, é possível identificar, segundo Perez; Martins (2012), resíduos gerados ao longo de todo o processo. No quadro 1 apresentado a seguir, são descritos os materiais que ingressam em cada etapa bem como os resíduos gerados.

Quadro 1- Resíduos em cada etapa

\begin{tabular}{|l|l|l|}
\hline ENTRADA & ETAPA & SAíDA \\
\hline $\begin{array}{l}\text { Pedidos de tecido } \\
\text { Papel }\end{array}$ & CONCEPÇÃO DE PRODUTO & $\begin{array}{l}\text { Papel, plástico (embalagens de tecido), } \\
\text { Tecidos não usados e resíduos de } \\
\text { papel. }\end{array}$ \\
\hline $\begin{array}{l}\text { Papel } \\
\text { Tecido }\end{array}$ & MODELAGEM E PILOTAGEM & $\begin{array}{l}\text { Resíduos têxteis, tubo de papel, peças- } \\
\text { piloto reprovadas. }\end{array}$ \\
\hline $\begin{array}{l}\text { Tecido } \\
\text { Papel } \\
\text { Fita Crepe } \\
\text { Etiquetas }\end{array}$ & CORTE & $\begin{array}{l}\text { Embalagem plástica de tecido, tubo de } \\
\text { tecido, rolo de etiqueta, fita crepe, } \\
\text { resíduos de papel, resíduos de tecido, } \\
\text { tecido com defeito }\end{array}$ \\
\hline $\begin{array}{l}\text { Pacotes de produção } \\
\text { Aviamentos }\end{array}$ & DISTRIBUIÇÃO E PREPARAÇÃO & $\begin{array}{l}\text { Linhas e fios cortados } \\
\text { papel do pacote }\end{array}$ \\
\hline $\begin{array}{l}\text { Tecido cortado } \\
\text { Aviamentos } \\
\text { Linhas e fios } \\
\text { Etiquetas }\end{array}$ & CONFECÇÃO & $\begin{array}{l}\text { Resíduos de linhas e fios, aparas de } \\
\text { tecido e peças não conformes }\end{array}$ \\
\hline $\begin{array}{l}\text { Tags } \\
\text { Peças Costuradas } \\
\text { Aviamentos }\end{array}$ & ACABAMENTO E CONTROLE \\
\hline $\begin{array}{l}\text { Peças prontas } \\
\text { Caixas } \\
\text { Sacolas plásticas } \\
\text { Tags } \\
\text { Papel }\end{array}$ & DE QUALIDADE & $\begin{array}{l}\text { Etiquetas de OP, resíduos de linhas e } \\
\text { fios, peças com defeito }\end{array}$ \\
\hline Pedidos embalados & EXPEDIÇÃO & $\begin{array}{l}\text { Sacolas rasgadas, peças } \\
\text { conformes, etiquetas de identificação, } \\
\text { papel, fita adesiva. }\end{array}$ \\
\hline $\begin{array}{l}\text { Produto acabado } \\
\text { CLIENTE }\end{array}$ & $\begin{array}{l}\text { Sacola } \\
\text { Descarte do produto }\end{array}$ \\
\hline
\end{tabular}

Fonte: Adaptado de Perez; Martins (2012). 
Como observado no quadro 1 , ao longo do processo de desenvolvimento e produção de uma coleção de moda, vários resíduos são gerados ao longo das etapas produtivas. Sabendo da elevada quantidade de material que poderia ser reaproveitada e é descartada, é importante que sejam geradas alternativas que garantam a melhor utilização dos materiais como papel, plástico, restos de linhas e tecido, mas que também comtemplem as peças de vestuário, que foram concluídas pelas costureiras nas empresas, mas que possuem pequenos defeitos e por esse motivo são reprovadas pelos setores de qualidade.

Neste sentido, como apontado na introdução deste estudo, nos últimos anos empresas do setor vem se preocupando em utilizar melhor os resíduos, tidos como sobras das próprias ou de outras confecções a fim de minimizar os efeitos no meio ambiente. Nas próximas seções deste estudo serão apresentados o processo de desenvolvimento e produção do produto de moda na marca Comas, que utiliza como condutor de suas ações o conceito do upcycling.

\subsection{Marca Comas}

Esta seção irá apresentar e analisar brevemente o processo de desenvolvimento de produto da marca Comas que utiliza o conceito mencionado para embasar suas criações. De acordo com a pesquisa bibliográfica, realizada em fontes de dados secundários $^{4}$, a marca é resultado de uma pesquisa iniciada pela proprietária, Augustina Comas ainda na universidade. A estilista foi aperfeiçoando seu método de criação de roupas ao longo dos anos, enquanto trabalhava para marcas de moda do Uruguai e do Brasil. Segundo Comas (2015) "a forma de conceber as roupas a partir do upcycling é fruto de trabalho, que uniu estudo, reflexão e o convívio com os alunos das oficinas que oferece no Brasil e no Uruguai".

A estilista da marca atua com a recuperação e recolocação de camisas masculinas que não passam pelo controle de qualidade nas fábricas de origem, por conta de defeitos como pequenas manchas e furos, e por esse motivo acabariam desvalorizadas. Para a marca Comas, esta sobra oriunda de fábricas de camisas masculinas, obtida por meio de parcerias, é a matéria-prima utilizada na produção de produtos de moda. Em recente entrevista ao Portal FFW (2015) a estilista e proprietária da marca Augustina Comas afirmou "que as peças produzidas e sua forma de atuação no mercado de moda vão de encontro a lógica do descartável" (COMAS, 2015).

O mix de produtos da marca inclui modelos de camisas femininas, saias e vestidos, produzidos a partir das camisas masculinas. Peças de jeans, linho, tricolines, chambray, fil-a-fil, oxford, entre outros tecidos, também fazem parte da linha da marca que preza pela produção de produtos duráveis, com estilo clássico e simplicidade (COMAS, 2015).

\subsection{Etapas do projeto}

\footnotetext{
${ }^{4}$ Segundo Prodanov (2006), considera-se um dado secundário reportagens, livros, cartas e registros estatísticos. Neste trabalho, usou-se reportagens e o registro da marca, disponível no site próprio.
} 
Nesta seção serão apresentadas as etapas do projeto de moda, desenvolvido na marca Comas. Salienta-se que os dados foram obtidos por meio de pesquisa bibliográfica, no site da referida marca e em reportagens acerca do processo produtivo desenvolvido pela estilista Augustina Comas. Esta profissional tornou-se referência para a produção de artigos de vestuário desta forma, especialmente no Brasil, onde o conceito do Upcycling ainda é pouco explorado por empresas do setor.

As etapas a serem esplanadas relacionam-se com as fases de planejamento, pesquisa, desenvolvimento, pilotagem e produção, apresentadas no referencial teórico deste trabalho, com referência em Treptow (2013).

Com relação ao planejamento dos produtos, em entrevista recente, a estilista da marca Comas comentou que o projeto de desenvolvimento inicia com a aquisição de camisas masculinas nas fábricas de origem. A estilista Agustina, recolhe as peças reprovadas nas confecções, as seleciona buscando camisas com tecidos de qualidade, passíveis de transformação, e depois realiza um estudo de modelagem a fim de conceber as peças. Num segundo momento, ocorre a pesquisa para identificar os tecidos e posteriormente a confeç̧ão adequada, detectando quais alterações serão necessárias para cada peça. O desafio, segundo a estilista, é selecionar peças que têm maior potencial de transformação (FFW,2015).

No estudo criativo da marca que origina a etapa de desenvolvimento, as peças de vestuário que já estão costuradas, porque foram reprovadas no setor posterior ao da costura, são modificadas primeiramente por meio de uma tabela de medidas feminina, construída pela própria Augustina Comas. As alterações são relacionadas a larguras e comprimentos das peças, que são revistos para atenderem ao público feminino, foco da marca (COMAS,2015).

A alteração de medidas é um trabalho manual, onde a estilista altera peça por peça. As camisas utilizadas, por terem sido reprovadas em um controle de qualidade, possuem pequenos defeitos como manchas provenientes de processos de tingimento inadequados ou furos resultantes de cortes errôneos ou desmanches de costura ${ }^{5}$. (COMAS, 2015).

Em seguida a alteração de medidas, as peças seguem para a etapa de produção, onde a costura é realizada a mão ou por uma costureira em máquina. É importante enfatizar, que as alterações são sutis e reportam-se ao encurtamento do comprimento de medidas de corpo e de manga, ao ajuste de medidas com pences, a exclusão de algum detalhe da peça, como por exemplo as mangas, ou a utilização de retalhos de uma peça como detalhe em outra. A ideia que permeia a marca, além de valorizar e dar nova vida as peças que seriam descartadas, está em modificar sutilmente as peças, afim destas não perderem suas características iniciais. (COMAS,2015).

Após a conclusão da costura, as peças são fotografadas em editoriais de moda, normalmente ao ar livre, como meio de divulgação e posteriormente fotografadas em

\footnotetext{
${ }^{5}$ Os furos provenientes de desmanches de costura resultam de duas situações. A primeira refere-se a pressa da costureira em desmanchar, causando esgarçamento no tecido. A segunda, aponta para o uso inadequado de agulha, comum em tecidos leves como a seda ou frágeis como alguns tipos de flanela, que necessitam de uma agulha com a ponta muito fina para uma boa costura.
} 
cabides para serem veiculadas no site da marca, onde são comercializadas. (COMAS, 2015).

Na Figura 1, é ilustrado a imagem de uma peça em editorial e para venda no site:

Figura 1- Peças da marca Comas.

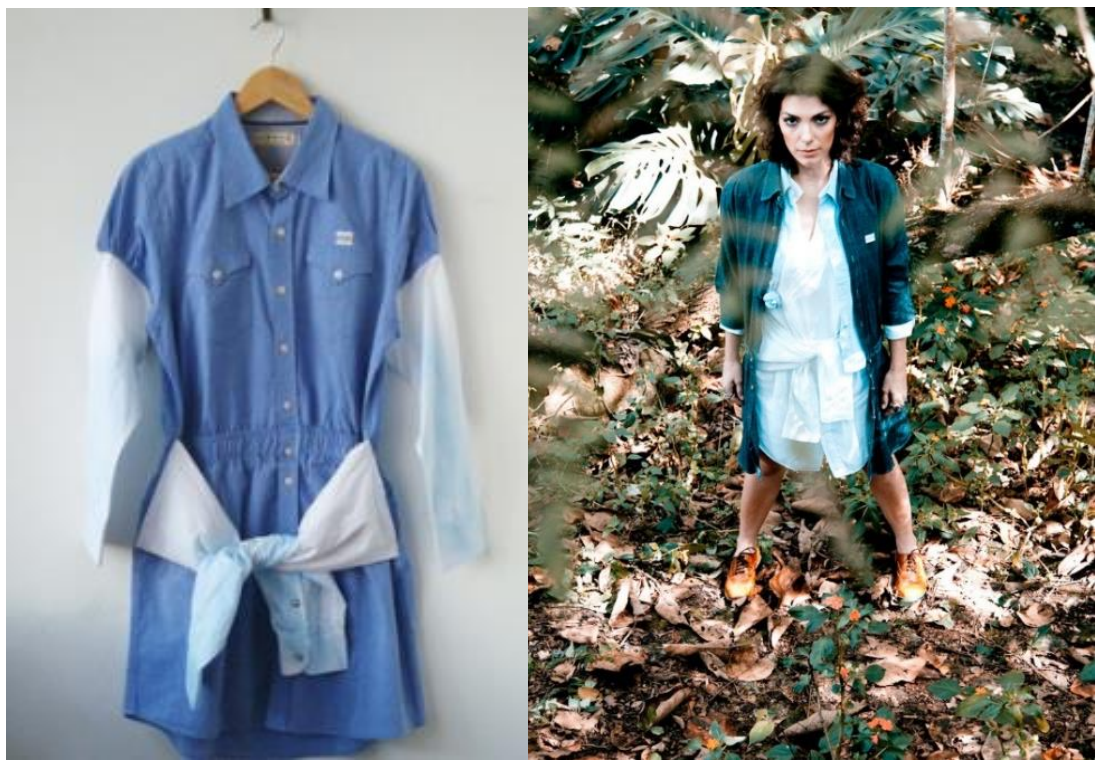

Fonte: www.comas.com.br (2015).

\subsection{Análise do processo}

O processo desenvolvido na marca Comas possui uma ordem cronológica, previamente definida e normalmente seguida nas execuções das peças. Como observado, a marca não trabalha com o desenvolvimento de coleções, mas sim com concepções individuais de produtos, que podem ser novamente desenvolvidos desde que as peças originais, reprovadas nas fábricas, sejam similares ou idênticas.

Salienta-se ainda que as etapas de processo têm como determinante as características das camisas masculinas que são adquiridas, visto que é a própria roupa que determina as modificações possíveis e o resultado final. $O$ fato de partir de peças prontas limita 0 trabalho da profissional do estilo, uma vez que a quantidade de tecido danificado pode ser superior à de tecido em boas condições.

Em contraponto, cada camisa masculina tem sua estrutura pensada anteriormente, pelo modelista na fábrica de origem e alterações errôneas ou sem estudo prévio podem não ter um bom resultado, especialmente pelo fato da marca Comas não desenvolver pilotagem das peças produzidas, já que as alterações definidas são efetuadas diretamente na peça pela costureira.

Ainda com relação a produção das peças, é importante mencionar que é identificável na marca, especialmente na estilista responsável pelas alterações, um apurado conhecimento em modelagem e em caimento de tecidos. Acredita-se que conceber produtos a partir de um vestuário pronto, como mencionado no parágrafo anterior, é mais difícil do que partir de um retalho de tecido. 
A marca Comas preocupa-se com os resíduos de todo o processo, não utiliza moldes de papel e realiza as alterações com marcações na própria peça de vestuário. Além disso, reaproveita resíduos de camisas como detalhes construídos em uma nova peça. Estes fatores potencializam os benefícios deste processo, promovendo agilidade além de diminuir custos com o papel e resíduos secos.

\section{CONCLUSÃO}

A motivação para realização deste trabalho nasceu da busca por melhoramentos no processo produtivo da indústria de moda, especialmente na de vestuário. Por vivenciar as etapas do processo em confecções e também no ambiente acadêmico, a autora deste estudo percebe o quanto as etapas produtivas de fábricas do setor promovem grandes emissões de poluentes, além da geração de resíduos em todas as etapas, como citado no referencial teórico.

No entanto, há alguns profissionais e marcas que vem preocupando-se especialmente com essas emissões e tem optado por produzir bens vestíveis de materiais mais naturais, com poucos corantes e lavagens. Mesmo assim, sabe-se que essas ações individuais de redução em etapas ainda não têm sido suficientes, pois a efemeridade de moda e de suas tendências impede que as empresas diminuam a oferta de produtos.

Neste sentido, buscando por materiais que ilustrassem o conceito de valorização do produto e de como pudesse ser aumentado o uso de produtos prontos, a autora encontrou subsídios de utilização do upcycling em uma marca de moda, que efetivamente guia seus passos baseada na valorização de camisas masculinas, partindo de parcerias com confecções produtoras, para então construir seu próprio produto de moda feminina.

Partindo da pesquisa bibliográfica realizada, acredita-se que a forma encontrada pela proprietária e estilista da marca para conceber seus produtos, além de demostrar preocupação com a redução de resíduos e ampliar o ciclo de vida das camisas masculinas destinadas a serem usadas por mais tempo, possui viabilidade técnica e comercial, uma vez que a logística criada pela empresa e o conhecimento técnico em modelagem permite a marca desenvolver as peças do seu mix de produto com êxito.

Espera-se com este estudo motivar uma discussão entre profissionais do design e design de moda para uma reflexão acerca de processos produtivos, seus resíduos e especialmente com relação ao uso do conceito upcycling, que neste trabalho mostrouse passível de incorporação em um negócio da área.

\section{REFERÊNCIAS}

ALVES, A. S. Design do vestuário: protótipo funcional para o encaixe de moldes no tecido. Porto Alegre, 2010. 172p. Dissertação (Mestrado em Design) - Programa de Pós-Graduação em Design, UFRGS, 2010. 
ANICET, A.; BESSA, P; BROEGA, A. C. Ações na área de moda em busca de um design sustentável. Anais do 70 Colóquio de Moda, Maringá, 2011. Disponível em:http://www.coloquiomoda.com.br/anais/anais/7-Coloquio-de-Moda_2011/GT11 /GT/GT89897_Acoes_na_area_da_moda_em_busca_de_um_design_sustentavel.pdf. Acesso em 20 de jul. 2015.

ANICET, A.; RÜTHSCHILLING, E. A. Relações entre moda e sustentabilidade. Anais do 9o Colóquio de Moda, Fortaleza, 2013. Disponível em: http://www.coloquiomoda.com.br/anais/anais/9-Coloquio-de-Moda_2013/ARTIGOSDE-GT/Artigo-GT-Moda-e-Sustentabilidade/Relacoes-entre-moda-esustentabilidade.pdf. Acesso em 20 de jul. 2015.

BNDES. Panorama da Cadeia Produtiva Têxtil e de Confecções e a Questão da Inovação. Disponível em: <http://www.bndes.gov.br/SiteBNDES/bndes/ bndes_pt/Institucional/Publicacoes/Consulta_Expressa/Setor/Complexo_Textil/20090 3_05.html >. Acesso em 07 de jul. 2015.

CHATAIGNIER, G. Fio a fio: tecidos, moda e linguagem. São Paulo: Estação das Letras, 2006.

FRINGS, G. S. Moda do conceito ao consumidor. Tradução de Mariana Belloli. Porto Alegre: Bookman, 2012.

MARTINS, G. B. H. Práticas Limpas Aplicadas às Indústrias Têxteis de Santa Catarina. Florianópolis, 1997. Dissertação de Mestrado - Programa de Pós-Graduação em Engenharia de Produção. Universidade Federal de Santa Catarina. 1997. Disponível em: < http://www.eps.ufsc.br/disserta97/geruza/>. Acesso em: 15 ago. 2015.

MARCA DE UPCYCLING. Portal FFW. Disponível em :< http://ffw.com.br/noticias/moda/conheca-a-comas-marca-fashion-de-upcycling-comvenda-online/>. Acesso em: 12 ago. 2015.

RECH, S. R. Cadeia produtiva da moda: um modelo conceitual de análise da competitividade no elo confecção. 2006. Tese de Doutorado - Programa de PósGraduação em Engenharia de Produção. Universidade Federal de Santa Catarina. Florianópolis, SC: UFSC.

Moda: por um fio de qualidade. Florianópolis: UDESC, 2002.

SANCHES, M. C. de F. Projetando moda: diretrizes para a concepção de produtos. In: PIRES, Dorotéia Baduy et al. Design de moda: olhares diversos. Barueri; Perdizes: Estação das Letras e Cores, 2010. p. 289-301.

SANTOS, N. E. S. Utilização da análise de "Filière" com a variável ambiental "Efluentes Líquidos e Estações de Tratamento" no estudo de comportamento das indústrias têxteis do Vale do Itajaí - SC. Florianópolis, 1996. Dissertação de mestrado- Programa de Pós-Graduação em Engenharia. Universidade Federal de Santa Catarina. Disponível em: < http://www.eps.ufsc.br/disserta98/ely/>. Acesso em: 15 ago. 2015.

PEREZ, I. U; MARTINS, S. B. Design de Moda: da concepção, desenvolvimento, produção a soluções sustentáveis. Relatório Final de projeto de pesquisa Inovação e 
sustentabilidade no aproveitamento de resíduos têxteis do APL de Londrina e Região, PROPPG, UEL, 2012.

PEZZOLO, D. B. Tecidos: história, tramas, tipos e usos. São Paulo: Senac São Paulo, 2007.

PRODANOV, C. C. Manual de Metodologia Científica. Novo Hamburgo: Feevale. 2006.

SOBRE COMAS. Portal Comas. Disponível em :<www.comas.com.br. Acesso em: 10 ago. 2015.

TREPTOW, D. Inventando moda: planejamento de coleção. D. Treptow, 5. ed. São Paulo: 2013. 207 p.

TONDOWSKI, L. O cuidado com as soluções "criativas". Revista Saneamento Ambiental. 54. ed. 1998. Disponível em:

<http://br.monografias.com/trabalhos/residuosindustriais/residuosindustriais.shtml\#r e sid>. Acesso em: 10 ago. 2015.

TWARDOKUS, R. G. Reuso de água no processo de tingimento da indústria têxtil. Florianópolis, 2004, 110f. Dissertação de Mestrado- Programa de Pós-Graduação em Engenharia. Universidade Federal de Santa Catarina. Disponível em: < http://notes.ufsc.br/aplic/enqteses.nsf/102c8948110842f303256eb5006c5489/d769f2 12c721b87e83256fd9003ff7ff?>. Acesso em: 10 ago. 2015. 